\title{
Intelligent Transportation System Architecture for a Carpool System
}

\author{
Kavita \\ Sheoran \\ (Guide) \\ Assistant \\ Professor / \\ Reader,CSE \\ Department \\ Maharaja \\ Surajmal \\ Institute of \\ Technology
}

\author{
Vaibhav \\ Jatana \\ Student, CSE \\ Department \\ Maharaja \\ Surajmal \\ Institute of \\ Rachit Gulati \\ Student, CSE \\ Department \\ Maharaja \\ Surajmal \\ Institute of \\ Technology
}

Technology

\author{
Nikhil Ahuja \\ Student, CSE \\ Department \\ Maharaja \\ Surajmal \\ Institute of \\ Technology
}

\author{
Ankit Kapoor \\ Student, CSE \\ Department \\ Maharaja \\ Surajmal \\ Institute of \\ Technology
}

\begin{abstract}
As a rapid increase in urbanization, many people can afford a car nowadays but due to increase in the number of cars in the city people are facing problems in travelling. Due to rapid increase in the number of cars not only congestion and traffic is increasing but also it is harming the environment. Also due to this it leads to problems like increase in fuel combustion, heavy cost on resources, parking problems. To overcome these problems an online solution of "CAR POOLING" has been proposed. We intend to make a web and android application that will let people know if vehicles are available for sharing in their desired path. Also ,it will facilitate people using this application to share expense and may not worry about hiring a cab or making new connections. People using this application on their mobile phone can easily carpool with unacquainted or acquainted people without much efforts and even without security concerns. Intelligent transportation technology can play an important role in making these systems user-friendly, easy to manage, and efficient. There is an important need to tightly integrate the different types of technology and to develop an effective system architecture.
\end{abstract}

\section{General Terms}

Intelligent Transportation System, Global Position System, Vehicular Adhoc Network, Radio Frequency Identification System, Car pool system.

\section{Keywords}

ITS, VANET, RFID, GPS, GPRS

\section{INTRODUCTION}

Shared vehicle systems have been an increasingly popular alternative transportation paradigm in recent years. The use of a private automobile in many cities is becoming more and more difficult due to increased congestion and a lack of (affordable) parking space. Public transportation modes can be an economic alternative, however they still lack the flexibility and availability of the private automobile. Shared vehicle systems have the potential to be both economical and flexible.

There are several different kinds of shared vehicle systems.

In general, a car pooling system consists of a private owned vehicle shared by multiple passengers headed for the same destination.

Reduction in vehicles required to meet total travel demand is a key advantage of shared vehicle systems. An added energy /emissions benefit comes when low-polluting (e.g. fuel) vehicles are used in the shared vehicle system. A more generalized shared vehicle system is one in which vehicles are shared among multiple people to go from one source to another. Such system may be set up in resort communities, recreational areas, university campuses and so on. In this type of shared vehicle system, the trips are more likely to be oneway each time. If shared vehicle systems (in particular multicheckpoint shared vehicle systems) are to be successful, they must be: 1) efficient; 2) user-friendly; and 3) manageable. If the system is not efficient, then the operational (and capital) costs will be too high. If they are not user-friendly, then people will not use the system and instead will use a different means of transportation [1].

\subsection{About ITS}

Intelligent Transportation System are intended to offer a variety of technological solutions to the growing surface transportation problems being experienced by more and more cities. Many countries have done a great deal of work in ITS. It requires application of information technology to transportation under the rationale of making better use of existing transportation infrastructure by providing more accurate, timely and alternative use-information to transportation users [1].

Intelligent Transportation System (ITS) technology can be applied to shared vehicle system. There are several ITS technology "bundles" that can be applied to shared vehicle systems which includes :

- intelligent communication and tracking systems to provide vehicle location and identification.

- reservation and dispatching systems so that users can receive system information, check-out vehicles, and make reservations over the internet, by phone etc.

- travel and on-board navigation information to assist users operating within a shared vehicle system.

\subsection{Countries implementing ITS}

With the development of communication technology, recently, a lot of attempts related to Intelligent Transport System have come forth at home and abroad. Many countries have done a great deal of work in ITS. In 1992, the US Congress brought into effect the Intergovernmental Surface Transportation Efficiency Act, which provided significant funding for the application of information technology to 
transportation under the rationale of making better use of existing transportation infrastructure by providing more accurate, timely and alternative use-information to transportation users. Parallel to this early '90s program in the US were a series of programs in Europe conducted under the term of Telematics and led by the inter-European coordinating agency. .Similarly Japan had major activities in this area under the VERTIS organizing group. From a global perspective ITS programs have continued to evolve and the sixth World Congress in ITS had been held in Toronto, Canada in November 1999. [2]

In China, the state Development Planning Commission has definitely presented the long-term strategic target of transportation development: Establishing the Intelligent Integrated Transportation System (IITS) .

\subsection{Other ITS Based System}

There are several other ITS systems available as stated below:

\subsubsection{GPRS and Bluetooth based system}

With the development of communication technology, recently, a lot of attempts related to Intelligent Transport System have come forth. Based on the exploration of wireless communication in the intelligent public transport system, a hybrid model of GPRS and Bluetooth is provided which is fast, stable and secure and a new model of intelligent public transportation system is established on the existing transportation model. It introduces the system of composition and working principle, and completes the design and implementation of system. This model of communication has been used in the actual project and has achieved certain results.[5]

\subsubsection{Vanet based system}

Vehicular Adhoc Network (VANET) is wireless communication between vehicle to vehicle and vehicle to roadside infrastructure based on wireless local area network (WLAN) technology. VANET protocols are designed in such a manner that in emergency situation it not only help driver come out of traffic jam and give information about alternate route to destination but also during accidents, same or adjacent node (vehicle) inform roadside infrastructure and other vehicles about accidents. IVC works like a multi-hop mobile ad hoc network (MANET) with its own unique characteristics.

\subsubsection{RFID Based System}

This ITS based system is on traffic control .In the metropolitan cities like Kolkata, Mumbai and Delhi there are major problems like malfunction of traffic control and various security issues .This system suggests an automated user friendly traffic control system which will detect a vehicle using the RFID active tag attached to the vehicle and as soon as the vehicle passes by a reader, this process will identify each vehicle reducing traffic malfunction and also reducing security problems. This can only be possible by the use of RFID tickets and mesh network can be used to make the traffic control smooth and travelling very precise. It basically deals with the identification and positioning of the vehicle for automated traffic control system.[7]

\section{RELATED WORK}

\subsection{Congestion control in Delhi}

There is a rapid trend in urbanization in India .As a consequence more people than ever before will be living and working in cities, but also more people and more goods will be taking more time and longer trips in urban areas. This increasing dependence on cars is resulting in more road building expenses and maintenance, congestion and clogging on roads, high consumption of energy along with increased economic and environmental costs, causing air and noise pollution, traffic accidents. Traffic congestion is a major trouble for the professionals in India during transportation and there has been not much attempt made to quantify the growth of congestion in different cities in India. Delhi has the third highest population among cities in India . [1][3]. The total number of vehicles in Delhi (7.2 million) was more than number of vehicles in cities like Mumbai (1.5 million), Calcutta (1.8 million) and Chennai (3.5 million) put together during March 2011 so there is need of a efficient system to reduce traffic in Delhi [3].

Table I : Distribution of Population and Vehicles in Delhi [4]

\begin{tabular}{|c|c|c|c|c|c|}
\hline \multicolumn{6}{|c|}{ REGISTERED MOTOR VEHICLE IN DELHI } \\
\hline 2009-10 & 2010-11 & 2011-2012 & 2012-13 & S.NO. & NAME OF VEHICLE \\
\hline 6 & 7 & 8 & 9 & & 1 \\
\hline 2013680 & 2173323 & 2343113 & 2474087 & 1 & CARS AND JEEPS \\
\hline 4055229 & 4342403 & 4644146 & 4962507 & 2 & $\begin{array}{l}\text { MOTOR CYCLES AND } \\
\text { SCOOTERS }\end{array}$ \\
\hline 86482 & 88181 & 88197 & 86838 & 3 & AUTO RICKSHAWS \\
\hline 45240 & 57958 & 69780 & 70335 & 4 & TAXIS \\
\hline $58047^{*}$ & 61471 & 64033 & 39694 & 5 & BUSES* \\
\hline 193205 & 209370 & 228886 & 140942 & 6 & GOODS VEHICLES ETC \\
\hline 6451883 & 6932706 & 7438155 & 7774403 & & TOTAL \\
\hline & $\begin{array}{l}\text { NOTE:- } \\
\text { SOUR }\end{array}$ & INCE \& 0 & NGER & & \\
\hline
\end{tabular}

There are various problem associated due to the absence of an efficient transportation system in urban areas like ownership and utilization of personalized motor vehicles to commute is increasing at an alarming rate which is not only more energy intensive and harmful to environment, but also more expensive to the economy and it leads to higher oil consumption and emissions that are poisoning the urban areas so car pooling is the solution as Carpooling system is very effective means to reduce pollution and the congestion of vehicles in cities. It also provides an eco-friendly way to travel, provides an opportunity to meet new people and if used efficiently would decrease time to travel in urban areas where there is heavy traffic on roads because today most of the people prefer private vehicle to travel due to delay caused in public transport system and luxuries provided by private vehicles.

\subsection{Enhanced security for women passengers}

To provide safety for women our system can be enhanced with the feature of GPS tracking. With carpooling, car can be shared by unknown people. Nowadays there are severe security problems in traffic system due to anti social elements, so there is a requirement of security feature in our system. With GPS tracking a guardian can track the location of pooled car and also that would allow women to contact authorities by sending their location of pool point. It determines the precise location of vehicles, persons or other assets and records the position at regular intervals to be displayed against a map 
backdrop either real-time or when analyzing the track later, using GPS device in mobile phones.

\subsection{High reliability due to real-time tracking}

GPS location technology is widely chosen in vehicle monitoring systems of the city. Latitude and longitude of the location of vehicles tested out by receiving satellite signals from the vehicle terminal and the measurement is sent to control centre through wireless communication network. By the analysis and processing, the location of the vehicle is shown in the electronic map, by obtaining the longitude and latitude.

\subsection{Parking space}

Carpool system is also helpful in optimal utilization of parking space. With this system we were able to manage the parking space in our institution more profitably. Due to carpooling lesser number of cars were parked in our institution and lesser space was required than before car pooling.

Table II: Reduction in utilization of parking space via car pooling

\begin{tabular}{|c|c|c|c|c|c|c|}
\hline $\begin{array}{l}\text { Total } \\
\text { No. of } \\
\text { people } \\
\text { visiting } \\
\text { the } \\
\text { campus } \\
\text { by car }\end{array}$ & $\begin{array}{l}\text { No. } \\
\text { of } \\
\text { cars } \\
\text { visiti } \\
\text { ng } \\
\text { the } \\
\text { cam } \\
\text { pus } \\
\text { befo } \\
\text { re } \\
\text { carp } \\
\text { ool } \\
* *\end{array}$ & $\begin{array}{l}\text { Space } \\
\text { utilise } \\
\text { d } \\
\text { (befor } \\
\text { e } \\
\text { carpo } \\
\text { ol)** } \\
*\end{array}$ & $\begin{array}{l}\text { No. } \\
\text { of } \\
\text { cars } \\
\text { pool } \\
\text { ed }\end{array}$ & $\begin{array}{l}\text { No. of } \\
\text { Non- } \\
\text { poole } \\
\text { d cars }\end{array}$ & $\begin{array}{l}\text { No. } \\
\text { of } \\
\text { cars } \\
\text { visiti } \\
\text { ng } \\
\text { cam } \\
\text { pus } \\
\text { after } \\
\text { carp } \\
\text { ool * }\end{array}$ & $\begin{array}{l}\text { Space } \\
\text { Utilise } \\
\text { d } \\
\text { (after } \\
\text { carpoo } \\
\text { 1)*** }\end{array}$ \\
\hline 400 & 200 & $\begin{array}{l}9600 \\
\text { sq } \\
\text { feet }\end{array}$ & 40 & 120 & 160 & $\begin{array}{l}7680 \\
\text { sq feet }\end{array}$ \\
\hline
\end{tabular}

NOTE: *Each pooled car have 4 members approximately

** Non pooled car have 2 members approximately

*** Space required by each car is roughly $48 \mathrm{sq}$ feet

\section{SYSTEM DESIGN}

This application is for two types of users: Car owner and Passenger. The passenger or the owner has to register themselves if they are using the application for first time. If they are already registered they have to login using their login id and password. During login, they have to select whether they are owner or passenger.

Car Owner:- a person who can register its own car for car pooling by entering its details such as type of car, seat availability ,ID proof, address and so on. Passenger:- a person wanting to pool a car will enter its details and can select the type of car and the area from where he/she can share the car.

If user is a owner then the details of carpool will be filled and it will be stored in database. A car owner visits the system and uploads his/her car with its starting area and destination specified. He provides the list of checkpoints from where the car will navigate through, so that passengers can get to know from where they can pool the car. When passengers login into their account they provide the account and travelling details and their location from where they have to pool the car. Passengers gets a list of cars with the unique id where passenger can select a car to pool according to their comfort .A map is displayed with the respective car id showing the path of travel where passenger can select its checkpoint to pool. After selection and submission car owner gets the details about the passengers who pooled its car and passengers conform their location to pool. Android users can also navigate to this website using their smart phones via mobile app. The main idea of providing interface through Android mobile phones is that GPS can be used to keep track of the vehicle which would enhance security. This application can also make use of an algorithm for example: Dijkstra Algorithm to find the shortest path so that one spends minimum amount of fare and can also make use of messaging services (SMTP server) to inform the passengers about the late arrival of car owner due to traffic or when car owner is not willing to go.

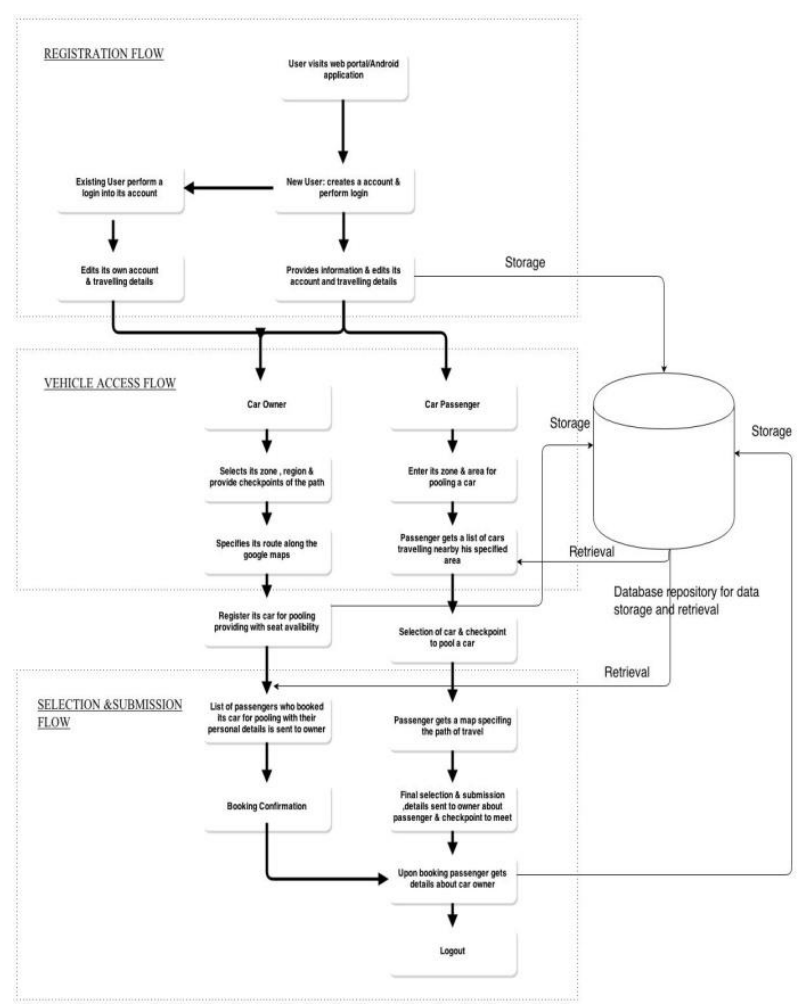

Figure I : Proposed model of carpool system

\section{PROPOSED SOLUTION CARPOOL USING ANDROID}

To provide an interface through mobile phones for ease of use a user can also access the system with the help of android mobile phones wherein a interface would direct the user to the system directly. With the help of this mobility feature a user can access the system dynamically from anywhere. A mobile application is designed specifically for mobile users which would navigate the control to the web interface.[8] 


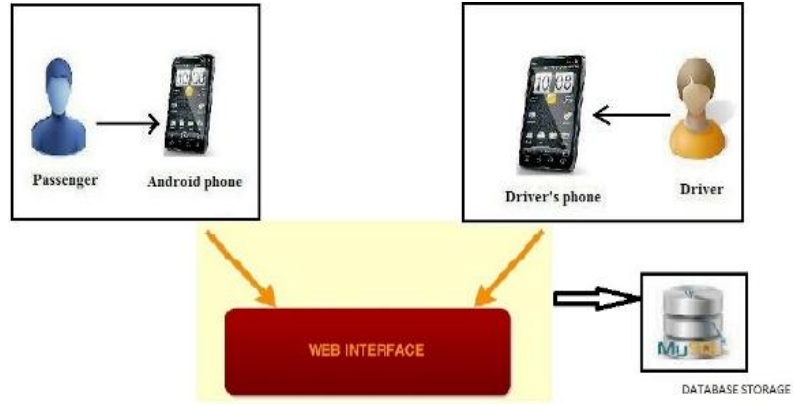

Figure II: Interface to the system through android mobile phones

\section{RESULTS AND ANALYSIS}

The application will help in reducing the pollution and traffic problem. It will cut-down personal expenses and cost. It has overcome the problems like traffic congestion ,fuel combustion ,parking space and pollution. It has several advantages such as reduction in fuel consumption ,usability ,cost ,communication with unacquainted people, security and reliability.

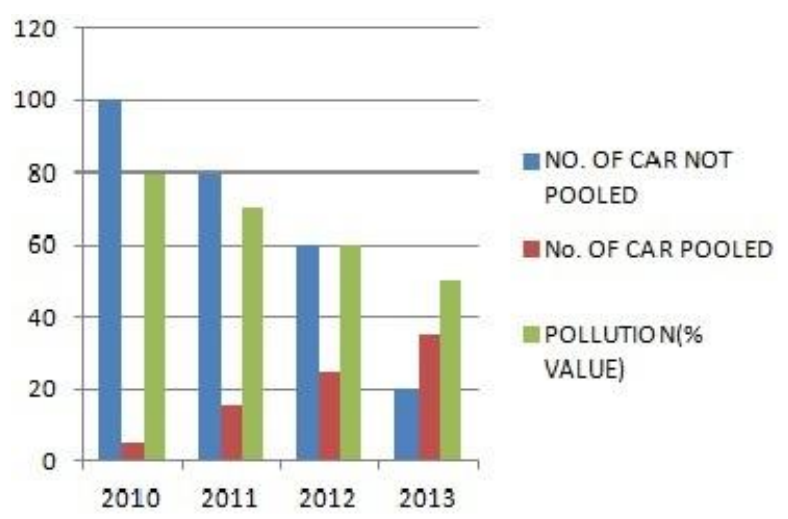

*SURVEY OF COLLEGE CAMPUS

Figure III : Survey and Results

\section{CONCLUSION AND FUTURE WORK}

We have made an application of Carpooling system which is a very effective solution to reduce traffic and pollution in cities, also it provides an eco-friendly way to travel. It provides an opportunity to meet new people. There are delays faced while travelling via public transport and therefore people nowadays prefer private vehicles. Pre registration of cars is done before commuting as it ensures that only identified people get into the vehicle so that trust can be established. The owner who registers its car specifies days on which they would take their private vehicle, so that no trouble is caused to the registered passengers for daily commute. This car pool system is very efficient for pooling cars and is beneficial as well as economical as it leads to less pollution ,less travelling costs and saves time to reach the destination. An architecture of the system is also provided in this paper which is a proposed model of the system. To provide more secure carpooling some more enhancements could be done in the system which could include tracking of pooled cars for surveillance by the guardians of pooled members.[6]

\section{REFERENCES}

[1] M. B. a. M. Todd, "Intelligent transportation system architecture for a multi-station shared vehicle system Intelligent Transportation Systems, 2000. Proceedings. 2000 IEEE," in IEEE Intelligent Transportation Systems, Dearborn (MI), USA, 2000

[2] IEEE, "Agent Based Intelligent Transportation Management," in International Conference on ITS Telecommunications Proceedings, 2006.

[3] K. K. Dewan and I. Ahmad, "Carpooling: A Step To Reduce Congestion(A Case Study of Delhi)," in Engineering Letters, 14:1, EL_14_1_12, 2007.

[4] D. s. Handbook, "www.delhi.gov.in," 2013. [Online].Available:http://www.delhi.gov.in/wps/wcm/co nnect/doit_des/DES/Our+Services/Statistical+Hand+Boo $\mathrm{k} /$.

[5] Song Jie, Li Na-na, Chen Ji-lin, Dong Yong-feng, Zhao Zheng,"Design and Implementation of Intelligent transportation system based on Gprs and Bluetooth," Qingdao, China, 2008.

[6] S. B. S. C. N. K. Arpita Dixit, "Real-Time Carpooling System for Android Platform," International Journal of Engineering and Innovative Technology (IJEIT), vol. 2, no. 6 , pp. 436,437, 2012

[7] P. B. T. Saurabh Chatterjee, "RFID based Traffic Contro System using ARM," International Journal of Advanced Research in Computer Science and Electronics Engineering (IJARCSEE), vol. 1, no. 10, pp.

[8] S. N. B. A. A.Mahapadi, "Review Paper On CarPooling Using Android Operating System-A Step Towards Green Environment," International Journal of Advanced Research in Computer Science and Software Engineering, vol. 3, no. 4, pp. 54-57, 2013. 